\title{
Quantitative Approaches on Staff Scheduling and Rostering in Hospitality Management: An Overview
}

\author{
Marta Rocha, José F. Oliveira, Maria Antónia Carravilla \\ INESC TEC, Faculdade de Engenharia, Universidade do Porto, Porto, Portugal \\ Email: \{marta, jfo, mac\}@fe.up.pt
}

Received October 12, 2011; revised November 17, 2011; accepted November 30, 2011

\begin{abstract}
Staff scheduling and rostering problems, with application in several application areas, from transportation systems to hospitals, have been widely addressed by researchers. This is not the case of hospitality services, which have been forgotten by the quantitative research literature. The purpose of this paper is to provide some insights on the application of staff scheduling and rostering problems to hospitality management operations, reviewing existing approaches developed in other similar areas, such as nurse rostering or examining adaptable problem models, such as the tour scheduling.
\end{abstract}

Keywords: Hospitality Management; Staff Scheduling; Rostering

\section{Introduction}

Hospitality is not a recent activity. In the social sense of the concept it dates from ancient times, where many societies had traditions of traveler protection and welcoming. King [1] overviews historical and sociological roots of hospitality and proposes a model emphasizing the importance of relationships between individuals (hosts, guests/customers, employees) in any hospitality context, whether it takes place in a private or in a commercial setting.

Hospitality and hospitality management have been the scope of many research articles, essentially in the social sciences field, where the discussion has been focused on a common and generically accepted definition and on the development of a framework to be the basis of an independent academic discipline.

Although still being often merged with tourism and leisure sector activities, hospitality services are a growing activity sector in a society where customer's satisfaction and well-being run the market. They usually include hotels, restaurants and other sort of lodging, food and drinks services providers. Due to the specifications of the kind of service provided, hospitality management has to deal with complex variables and constraints. An unpredictable customer demand, a multiskilled workforce, different staff labour contracts' demands, employees satisfaction and costs minimization are just some of the conditioning issues that an organization has to deal with in order to achieve a flexible, profitable and quality service provision.

A survey undertaken by Enz [2], in cooperation with the Center for Hospitality Research of Cornell University, identified human resources management as the most concerning issue for hotel managers, above other aspects such as economic or environmental problems, regardless of geographical location. The study was based on the statement of 243 experienced hotel executives from six countries. This highlights the importance and worldwide relevance of human resource management to a hospitality organization.

Staff scheduling and rostering are typical problems to solve within this area. There is however a big lack of published articles focusing these problems applied to the hospitality sector, as realized by Ernst, Jiang, Krishnamoorthy and Sier [3], in opposition to other application areas such as hospitals, transportation or call centers.

The aim of this paper is to share some findings on the application of staff scheduling and rostering problems to hospitality management operations. An overview on how hospitality management, staff scheduling and rostering topics are discussed in the research literature is given, reviewing existing approaches developed in similar application areas as well as analyzing other problem formulations, with analogous characteristics, that are potentially adaptable to the problems under discussion.

\section{Hospitality Management}

One of the reasons for the lack of research articles focusing staff scheduling problems in hospitality is perhaps the lack of a consensual and generically accepted definition of the activity itself. Etymologically, the word hospitality, in Latin hospitalities, has its origin in hospes or 
hospitis (genitive), which means foreigner or guest. Dictionary definitions include "cordial and generous reception of or disposition toward guests" [4] and "kindness in welcoming strangers or guests" [5]. It is synonym of hospitableness and widespread used to define welcoming host-guest relationships, being thus traditionally associated with cultural and social values of each community.

In the industrial context, the term hospitality has been adopted mainly in the English-speaking countries to refer to the activity of hotels, restaurants and other sort of lodging, food and drinks services' providers, whether it takes place in a public/commercial or in a private/social context. Lashley [6] argues that this framework can be understood as an effort to "create a more favorable impression" of these activities, promoting a further hospitable commercial activity and letting the profit provision motivation remain in the background. While British researchers have traditionally based the discussion on this definition, American academics tend to use a broader meaning of hospitality, associating these activities with others under the tourism field, such as travel, leisure or entertainment.

In a first essay, hospitality management would then be intuitively defined as the management of those hospitality activities. In concordance, Brotherton and Wood [7] write that hospitality management is a generically used expression to easily replace other labels such as "hotel management", "restaurant management" or "catering management", but consequently none or few reflection has been given to the genuine meaning or nature of hospitality. They state that hospitality research has been characterized throughout the years by an unsystematic and scattered analysis, rendering a meaningful synthesis very hard to achieve.

In the academic community, researchers have been seeking out the development of the specialist discipline of hospitality management that would embody a theoretical framework and link it to the industry sector, but the lack of a consensual definition of hospitality has effectively been a barrier both to research progress ([8] and [9]) and to the creation of a robust and mature branch of learning. The discussion has been driven by some authors into the field of cultural and social sciences (see [10-13]), incorporating in the debate the importance of studying hospitality from a wider perspective rather than the commercial one. The contribution of authors from different fields of research and their vision's diversity could potentially be a major value but it could also be understood as a reflex of a fragmented and unstructured hospitality research.

King [1] introduces a hospitality model based on the interaction of social "rituals" in the commercial operation, associated with the process of the guest arrival, welcoming and departure. The author defines hospitality as a host-guest relationship between individuals, taking place in a commercial or private setting, whose success is assessed by the clear perception of the guest needs and their genuine satisfaction by the host. This perspective underlies an unconditional moral duty of hospitable behavior that can, at the edge, merge the meanings of hospitality and hospitableness, which Brotherton [10] contests, arguing that hospitableness has a much broader scope than hospitality activities. In fact, hospitable concerns are a competitive advantage in any activity that directly deals with customers, whether it is from the hospitality sector or not.

Believing that hospitality is a time evolving phenomenon, i.e., that hospitality' characteristics change over time, Brotherton [13] presents a conceptual model for hospitality comprising four dimensions: spatial, behavioral, temporal and physical. These dimensions help to analyze the extent of hospitality in terms of place of occurrence, motivational aspects, time and material features involved. In this conceptual model, the nature, incidence and forms of hospitality in a particular society in any given time period, expressed by domestic or commercial hospitality behavior, are a function of the human and natural resources available, which in turn are conditioned by the economic, socio-cultural, politico-legal and technological conjuncture. The author tried to operationalize this model through case studies (see [7]) in two hotels and later in two fast food restaurants, where guests/ customers where asked to participate through an interview, associating words that best fitted their notion of hospitality. Although this exercise didn't produce statistically significant results in terms of the influence of social factors (like age, gender, occupancy, etc.), it did provide inputs for understanding guests' perception of the meaning of hospitality that still needs to be further explored.

The comprehensive approach of studying the commercial hospitality activity from a wider social sciences perspective has indeed been quite controversial, as it turned out to happen after the publication of the book "In search of hospitality: theoretical perspectives and debates" by Lashley and Morrison [14]. The referred work presents the nature of hospitality from several views, from Anthropology to Marketing, and proposes an integrated "three-domains approach": the private, the social and the commercial domains. The main idea of this conceptualization is to consider and evaluate the effect of the social and cultural dimensions of hospitality in the commercial or business activity, despite their blurred boundaries. The book also defends the existence of hospitality management as an independent activity, apart from any other management activity.

Slattery [15] is one of the most critical researchers of this approach, arguing that it overestimates the social 
side in relation to the economic one and "excludes the hospitality industry context”. His classification model of hospitality industry is based in the place where activities effectively take place: Free-Standing Hospitality Business (hotels, restaurants, bars), Hospitality in Leisure Venues (casinos, cinemas, health clubs), Hospitality in Travel Venues (airports, bus stations, trains, ferries) and Subsidiary Hospitality (workplaces, health care, education). He thus considers that confining hospitality to lodging, food and drinks activities falls short since hospitality necessarily undertakes the management of several other sort of leisure activities associated with them, in order to respond to the increasing complexity of customer demand.

In his review, Jones [12] identifies five main hospitality schools of thought: science model, management, studies, relationship and systems, attesting that the state of hospitality research is not yet consolidated and there is a lack of consensus concerning its definition. Even though this diversity of thoughts persists, the management perspective was recognized to be in a dominant position in relation to other emerging views. But even in the management point of view the author finds three different approaches, with their main divergence in the focus of the research. While the traditional point of view considers hospitality to be a sub-discipline inside the main management disciplines, a different conviction uses hospitality as an application of the main discipline and a third perspective assumes a "multidisciplinary approach" studying hospitality from several different main management subjects.

In a recent article, Ottenbacher, Harrington and Parsa [16] analyze the pedagogical and research implications of defining the hospitality discipline. Based on a services marketing perspective, the authors defend a taxonomical classification, considering hospitality as a field supported by the economic output of a group of six related industries: lodging, foodservices, leisure, travel, attractions and conventions. Each of these independent industries takes, in turn, "input from hospitality either directly or indirectly for its survival and success." The article suggests the need of exploring separately each one of these activities, which are often ignored in literature, recognizing the diversity of their constitutive market segments.

\section{Staff Scheduling and Rostering}

\subsection{The Problem}

Wren [17] defines scheduling as "the allocation, subject to constraints, of resources to objects being placed in space-time, in such a way as to minimize the total cost of some set of the resources used" and rostering as "the placing, subject to constraints, of resources into slots in a pattern. One may seek to minimize some objective, or simply to obtain a feasible allocation. Often the resources will rotate through a roster. (...) Once shifts have been produced showing the daily work of personnel, these shifts are placed into a roster to show which shifts are worked by individuals on particular days". The author considers rostering, as well as timetabling and sequencing, as special cases of scheduling, which in turn refer to both the generic scheduling problem and also to some of its specific types. Despite this differentiation, he recognizes that these terms tend to be generally used in a non-rigid way. A quick look at published articles shows that rostering is typically associated with the allocation of people (human resources) while the objects of scheduling may vary from human resources, to vehicles, to machines, to examinations, to jobs, etc. In a simple manner, the rostering process can be defined as the assignment of the right people to the right task, to the right time and to the right place, usually at the minimum possible cost.

Several designations can be found in the literature to refer the problem of allocating human resources to work schedules or shifts. Those include staff, workforce, labour, employee or personnel scheduling/ rostering problem. This is a particularly relevant problem for the services activity sector, which is typically labour intensive, and has been the scope of interest of many research groups. A far-reaching review on applications, methods and models of rostering problems may be found in [3] and [18].

In the context of manufacturing organizations, systematic or standard approaches to tackle staff rostering problems are commonly applied. But in the case of service industries it is not so simple. In service operations there is no mass production, every service delivery is unique. While in manufacturing, products have rigid specifications in terms of physical dimensions, shape, etc., services attributes are intangible and service provision is affected by several human subjective factors that distinguish one from another, such as the mood of the receptionist in a hotel in a specific day or the noise of other customers in a restaurant, for example. Another key difference between these two activity sectors is the ability to fit demand. While in a manufacturing company, products can be held in stock allowing a flexible response to demand fluctuations, in pure service operations the "product" is both "produced" and "consumed" at the same time.

The complexity of the staff scheduling and rostering problem in service activities is mainly due to the variability of the demand and also due to its constraints, namely those directly related to employees' preferences in terms of working or rest days, to incompatibility between staff elements or between tasks, or those related to workload balance or fairness between schedules. These concerns have impact in the employee' productivity and 
are particularly relevant in service organizations, where service delivery is directly affected by employees performance, but are usually treated as non mandatory and named soft constraints. Other constraints to this problem, such as legal regulations that are mandatory, are considered hard constraints. Causmaecker and Vanden Berghe $([19,20])$ propose a framework for the classification of personnel rostering problems in services. It considers three categories: personnel environment, which includes different types of personnel constraints and skills; work characteristics, which refers to coverage constraints and shift types; and optimization objective. Such a classification system allows the comparison of problems in terms of hardness and complexity, but also the evaluation of developed approaches.

The rostering problem is often addressed in literature in its several sub-problems, either independently considered or in a combined way. Basically there are three main challenges to tackle within this problem: demand levels that we need to know in order to plan the workforce requirements, a set of activities to organize in shifts and the assignment of the staff elements to shifts and also to the rest days.

Sub-problems of the rostering problem that can be found in literature include demand modeling, shift scheduling, days off scheduling, tour scheduling, crew scheduling, crew rostering, task assignment, shift assignment, staff assignment, rotating or cyclic workforce scheduling, among others.

Demand modeling consists in determining demand levels and translating them into staff requirements for each planning period, for each shift or for each task. It is an important part of the process although it is often tackled at a higher level of more strategic planning decisionmaking than the remaining short-term or operational subproblems of the rostering problem. A generic illustration of the demand modeling phase can be seen in Figure 1, where the number of employees for each of the working shifts (Morning, Afternoon and Night) is determined.

In some service operations, where customer arrivals are usually random and fluctuate throughout the planning horizon, forecasting, queuing theory and simulation techniques are widely used to determine demand levels and the respective staff requirements. A detailed insight into this topic with application in call centers can be found in [21].

On the other hand, in activity sectors such as transports, demand is modeled with basis in the requirements of a predefined list of individual tasks to be performed by an employee (driver). Demand modeling in nurse rostering, for example, is based in the number of staff required for each shift, which must be in compliance with predefined service ratios (ex: nurse/patient). In hotels only a part of the demand, corresponding to confirmed
Demand levels translated in staff r equirements
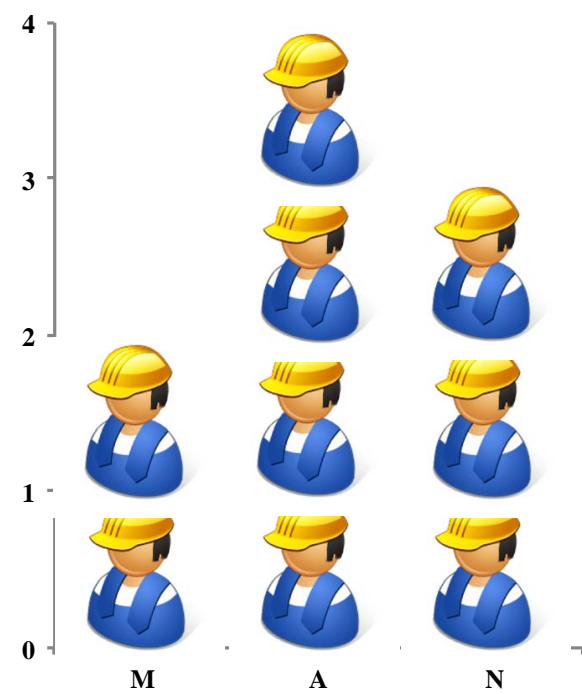

Shifts

reservations can be known beforehand. The remaining demand determination must be based on historic information and forecasting techniques. Of course, there is also the component of daily check-ins that must be considered.

The problems of crew and tour scheduling arise as the two most explored in literature ([3]). The tour scheduling problem combines in turn two other particular problems: selecting a set of shifts to be performed in the working days of the planning horizon, known as shift scheduling [22], and defining how rest days shall be interposed between them, which is called days off scheduling.

Crew scheduling and crew rostering are equivalent to the shift and tour scheduling problems respectively, when applied to transportation systems. In these systems the demand is determined based on a set of previously defined tasks. Another difference is the existence of an additional geographical or spatial dimension, usually associated to each task, which in this case can be the trips between two consecutive stops (buses, railways) or flight legs (airlines) that will be combined into round trips or pairings. See [23] for a recent survey on airline crew rostering problem types, modeling and optimization.

The tour scheduling problem is typically used in organizations that work continuously, 24 hours a day, 7 days a week, such as hospitals (nurse rostering) or hotels. Schedules are usually defined in a weekly basis. Figure 2 shows an example of the output of a tour scheduling problem with staff assignment. Staff assignment usually takes place in the last phase of the process, but it often can be done while constructing the lines of work.

In situations where the demand patterns repeat in a weekly basis, each line of the work schedule will rotate 


\begin{tabular}{|c|c|c|c|c|c|c|}
\hline \multicolumn{7}{|c|}{ Employees } \\
\hline $\mathrm{N}$ & OFF & $\mathrm{N}$ & OFF & A & A & A \\
\hline OFF & M & M & OFF & $\mathrm{N}$ & $\mathrm{N}$ & $\mathrm{N}$ \\
\hline M & M & M & $M$ & M & OFF & OFF \\
\hline OFF & OFF & A & A & A & M & M \\
\hline M & M & M & M & M & OFF & OFF \\
\hline A & M & M & $\mathrm{N}$ & OFF & A & OFF \\
\hline Mon & Tue & Wed & Thu & Fri & Sat & Sun \\
\hline
\end{tabular}

Figure 2. Example of tour scheduling.

through all employees with an offset between them. For example, employee number 2 will have the same line of work in week 2 that employee number 1 had in the week before. This is a cyclic rostering problem or workforce rotating scheduling problem [24]. A typical application of this problem is the bus or train driver scheduling problem, where timetables usually repeat weekly. In the opposite situation are call centers, where demand fluctuates every week and so rosters are acyclic. Cyclic rosters have the advantage of providing stability, employees know their schedule some time in advance and can plan their lives according to their future availability. On the other hand, they lack flexibility, being much less or even not adjustable to changes.

\subsection{Staff Scheduling and Rostering in Hospitality Management}

Staff scheduling and rostering problems have been explored in literature in many application areas, with emphasis on hospitals and transportation systems [3]. Hospitality, in turn, has had much less attention of researchers working in the quantitative field, with very few published articles, referring mainly to restaurants ([25-27]).

In an attempt to justify the relevance of staff scheduling for hospitality managers, Thompson proposes a fourstage method for the hospitality industry, which he presents in a four-article publication: forecasting demand [28], translating those forecasts into staff requirements [29], scheduling staff [30] and monitoring the schedule in real-time [31].

Choi, Hwang and Park [25] applied Thompson's framework to a restaurant, achieving a labor cost reduction and an increase in overall efficiency. The model had some simplifications though, not considering for example employees' preferences or availability.

The staff rostering problem in hospitality services shares common features with other service activities. It is quite noticeable, for instance, its similarity with the nurse rostering problem, so deeply explored in literature. Considering hospitality in its narrowest sense, as defined in the previous sections of this paper, which includes mainly hotels and restaurants, both problems seek to assign a set of employees to a set of working days, shifts and rest periods in order to satisfy demand levels, taking into account concerns regarding work rules, employees' skills, availability and preferences. The rostering problem both in hotels and hospitals is typically characterized by an around the clock operation, 7 days per week. The use of different contract types (e.g. part-time) is therefore a common and necessary practice.

Of course the place where it takes place and the set of conditions under which it can be found make the approaches to the rostering problem to be different in a hospital or in a hotel. The nurse rostering problem takes place in a hospital unit-a ward, where usually the different skill categories of the nurse function (e.g. head nurse, regular nurse, caretaker) need to be taken into account. The considered shift types are usually the conventional 7 or 8 hour shifts: early, late and night. Demand is usually determined with basis on desired service levels (e.g. nurse/patient ratios) or/and forecasting techniques and staff levels are defined for each shift and skill category. Workload distribution follows a daily pattern, usually ignoring weekends. Work rules are strict in terms of shift sequence, maximum/minimum number of consecutive assignments for each shift, periodicity of rest days, etc.

In addition to its lodging core operation, which involves several different functions (receptionist, concierge, doorkeeper, cleaning staff, maintenance operator, administrative staff) a hotel usually includes other activities such as restaurant, bar, leisure spaces, etc. The rostering problem in a hotel may also be applied to only a single functional area, for example the scheduling of the reception staff or the cleaning staff. There are situations, however, where staff is multifunctional and so an integrated approach is more appropriate, increasing the complexity of the problem to solve. It requires a high flexibility in terms of shift length, starting and finish times and needs to manage a bigger diversity of employee contract types as well as multiple functions. In what concerns work rules, just like in the case of hospitals, hotels and restaurants are very conditioned by sectorial union agreements or contracts, namely in terms of working and rest periods. In the current globalization context, multinational hospitality organizations, and specially hotels, must follow the motto: "think globally, act locally", meaning that although having general rules, common to all their units, each unit must have its organization and practice adapted to the local context where they are placed in. Different cultures and different habits usually mean different needs. In the hotels case, 
the majority of the reclaimed service levels are strategically imposed by its category (number of stars). Staffing needs must be determined based on the historic data, on guest arrival forecasts, on a slack for daily late arrivals but also based on the desired service levels.

In a similar way to the case of nurse rostering, important schedule's characteristics to take into account in hotels are: coverage, quality, stability, flexibility, fairness and cost [32]. Coverage indicates how faithful the schedule is to the requirements. The quality of a schedule is measured by each employee in terms of the satisfaction of its initial requests for that schedule. Stability and flexibility are somehow conflictual in the sense that they perceive opposite objectives: a stable schedule follows a rigid and predictable sequence while a flexible schedule is free enough to handle unpredictable changes. The fairness of a schedule is associated with the balance of the workload between employees and the cost is measured in terms of resources consumed in making the schedule. These characteristics, in particular quality, fairness, stability and flexibility are those connected to employees' preferences and therefore very important to guarantee a motivated and productive workforce. This is a critical issue in any customer oriented activity, and specially in services where there is such a deep interaction between employee/host and customer/guest, as is the case of hospitality operations. The perception of customer needs and their satisfaction is very dependent on the performance of every employee. Therefore, employees' welfare must be safeguarded.

\section{Possible Solution Approaches for Staff Scheduling and Rostering Problems in Hospitality Management}

One adoptable approach to the rostering problem in hospitality organizations, and in hotels in particular, is the tour scheduling problem. Several variations of this problem can be found in literature: models that consider full or/and part-time employees (see for example [33]), different employees' productivity levels ([34,35]), staff mixed skills and weekend off requirements [36], over and understaffing [37], relief (rest or meal) breaks [38] or shifts with a limited number of starting times $([39,40])$.

In a 2004 survey, Alfares [41] reviews approximately 70 tour scheduling papers published between the years of 1990 and 2001, comparing mathematical programming models and classifying them according to the applied solution methods. The most commonly used optimization formulation for staff scheduling and rostering problems is integer programming, based on general problems such as set covering [42] or partioning. These models are so general that can be adapted to several staff scheduling sub-problems such as days off, shift, tour or crew sched- uling and rostering. Integer programming techniques arise therefore naturally as one of the most used solution methods. The limitation on these exact approaches is that models are typically simplified versions of real problems. It is not possible to find optimal solutions in an acceptable time for problems with the size and the complexity of real nurse or hospitality rostering problems. In order to overcome this difficulty, implicit modeling, decomposition, constraint programming, column generation [26] and other techniques have been used by researchers with successful results.

In a survey work, Cheang [43], Burke, Causmaecker and Vanden Berghe [44] review models and solution approaches to the nurse rostering problem. According to both works, mathematical programming formulations (linear and integer) have been widely explored, with different objective functions, such as minimization of the staff costs [45]. Goal programming or multi-criteria approaches have also been applied in problems with more than one objective function or optimization criteria, but usually these techniques are used in combination with other methods, such as heuristics.

Improvement and constructive heuristics and metaheuristics are alternative approaches to optimization techniques. They tend to model real problems in a more accurate way and to give results in a reasonable time span, although they do not guarantee the achievement of an optimal solution. Goodale and Thompson [46] compare a set of heuristics to assign employees to the labor tour scheduling problem. The novelty of this work is that it takes into account the individual productivity and cost of each employee. Simulated annealing [47], tabu search [48] or genetic algorithms [49] are popular metaheuristics in the rostering literature, and nurse rostering in particular. The integration of optimization techniques with heuristic rules is also attracting the attention of researchers [50]. These commonly called hybrid approaches have proven to be a good solution, improving the performance of each of the different techniques.

Blöchliger [51] presents a tutorial on modeling staff scheduling problems. An example based on a nurse rostering problem is used to analyze and classify model elements: data requirements, notation, types of constraints and objectives. The objectives can have multiple components such as cost, fairness and soft constraint violations. Different types of constraints are considered: hard and soft, sequence, counting, job, incompatibility, local, global, intrinsic and extrinsic.

In the third of his four-paper work, Thompson [30] proposes a methodology for developing work schedules in hospitality organizations that seeks to balance both the organization's and the employee's goals. A comparison of two traditional approaches to staff scheduling, one by Dantzig [42] and the other by Keith [52], is presented 
and their limitations are pointed out. Two new methods are proposed, under two different perspectives: economic and service standards, with the goal of achieving the highest schedule's economic outcome and optimal service standards respectively. The main difference between these methods and the classic ones is that employee requirements are no longer independently set for each planning period but are now instead taken into account in both determination of demand levels and actual scheduling process. Assuming that a surplus employee cannot have the same cost or bring the same benefit/value no matter in which period he is added to, it is possible to maximize the level of service provided or developing the best schedule from an economic point of view, as defined by the organization. An emphasis is given therefore to the importance of satisfying employees' preferences, not disregarding their availability and skills and to the advantage of considering this information in the shifts development process. Thompson defends the use of a heuristic procedure in order to reach a good schedule in a reasonable amount of time in opposition to trying to find optimal solutions, which are typically too time consuming. The recommended planning horizon is one or two weeks, mainly due to the typical difficulties in predicting service demand more than two weeks in advance. Although presenting it as the outcome of a long work experience, Thompson does not apply this work to a practical case study. It would be interesting and certainly of great value to see the application of this approach in a hotel unit.

\section{Concluding Remarks}

Although hospitality and hospitality management are subjects that have been quite explored by social science researchers, they are not commonly referred in the operations research literature, or more precisely in the scheduling operations literature. But the truth is that there is a point in exploring rostering and scheduling problems in this area. First of all, because as in any other service activity, the importance of staff expenditure is typically very significant in the total operating costs of a hotel. Secondly, because the quality and efficiency of the service provided by a hotel or a restaurant have direct impact in its customers' satisfaction, as in few other service activities. The social dimension of hospitality that has been in the hospitality research agenda in the last decades, increases the complexity of staff rostering problems in this activity area. It is no longer only a matter of assuring the required employees' technical skills, but also of guaranteeing that they have the right personal competences to interact with customers, to understand and satisfy their needs. The staff must be motivated and engaged with the service. Staff scheduling systems shall therefore account for the workforce well-fare, considering employees' preferences in terms of work and rest days, weekends off and holidays, shifts assignment, shifts change, shifts starting and finishing times flexibility, compatibility or incompatibility with other staff elements, etc. Possible approaches to the staff scheduling and rostering problem in hospitality management, or its subproblems, may be inspired by the work that has been comprehensively done in both tour scheduling and nurse rostering. As exposed before in this paper, nurse rostering and hospitality are two activity areas with many similarities concerning rostering issues. Examples of the few divergences between them include the seasonality, the weekly and daily cycles operation inherent to hospitality activities, which contrast with the typical homogeneous workload distribution of hospitals throughout the year. Concerning solution methods, metaheuristic techniques have been gaining ground on optimizing approaches, although the announced trend is the use of hybrid approaches, taking advantage of the best of more than one single methodology. Thompson [30] gives a very important contribution to staff scheduling and rostering in hospitality management. It should have triggered the interest of researchers in this area, namely in the development of quantitative approaches, but the truth is that it didn't, according to the analyzed later reviews on this subject. This work aims to be a recall, there is still a lot to be done, future work may pass through the adaptation of tour scheduling, nurse rostering or even shift scheduling models and solution methods to hospitality operations. Schedules should be flexible enough to be easily adaptable to actual workplace environments changes and social concerns should be considered.

\section{REFERENCES}

[1] C. A. King, "Viewpoint-What Is Hospitality?” International Journal of Hospitality Management, Vol. 14, No. 314, 1995, pp. 219-234. doi:10.1016/0278-4319(95)00045-3

[2] C. A. Enz, "Key Issues of Concern in the Lodging Industry: What Worries Managers,” Cornell Hospitality Report, 2009.

[3] A. T. Ernst, H. Jiang, M. Krishnamoorthy, B. Owens and D. Sier, "An Annotated Bibliography of Personnel Scheduling and Rostering," Annals of Operations Research, Vol. 127, No. 1-4, 2004, pp. 21-144. doi:10.1023/B:ANOR.0000019087.46656.e2

[4] "Hospitality," The American Heritage Dictionary of the English Language, Online, Accessed 19 May 2011. http://www.thefreedictionary.com/hospitality

[5] "Hospitality," Collins Essential English Dictionary, Online, Accessed 10 May 2011. http://www.thefreedictionary.com/hospitality

[6] C. Lashley, "Studying Hospitality: Insights from Social 
Sciences," Scandinavian Journal of Hospitality and Tourism, Vol. 8, No. 1, 2008, pp. 69-84. doi:10.1080/15022250701880745

[7] B. Brotherton and R. C. Wood, "The Nature and Meanings of 'Hospitality'," In: The Sage Handbook of Hospitality Management, Sage Publications Ltd., London, 2008, pp. 35-61.

[8] P. Jones, "Viewpoint—Hospitality Research—Where Have We Got to?” International Journal of Hospitality Management, Vol. 15, No. 1, 1996, pp. 5-10. doi:10.1016/0278-4319(96)84544-0

[9] S. Taylor and D. Edgar, "Discussion Paper Hospitality Research: The Emperor's New Clothes?” Science, Vol. 15, No. 3, 1996, pp. 211-227.

[10] B. Brotherton, "Towards a Definitive View of the Nature of Hospitality and Hospitality Management,” International Journal of Contemporary Hospitality Management, Vol. 11, No. 4, 1999, pp. 165-173. doi:10.1108/09596119910263568

[11] N. Hemmington, "From Service to Experience: Understanding and Defining the Hospitality Business," The Service Industries Journal, Vol. 27, No. 6, 2007, pp. 747-755. doi:10.1080/02642060701453221

[12] P. Jones, "Finding the Hospitality Industry? Or Finding Hospitality Schools of Thought?” The Journal of Hospitality Leisure Sport and Tourism, Vol. 3, No. 1, 2004, pp. 33-45. doi:10.3794/johlste.31.55

[13] B. Brotherton, "Some Thoughts on a General Theory of Hospitality,” Tourism Today, No. 6, 2006, pp. 7-19.

[14] C. Lashley and A. J. Morrison, "In Search of Hospitality: Theoretical Perspectives and Debates," ButterworthHeinemann, Oxford, 2000.

[15] P. Slattery, "Finding the Hospitality Industry Part I: In Search of Hospitality," Journal of Hospitality, Leisure, Sport \& Tourism Education, Vol. 1, No. 1, 2002, pp. 1928. doi:10.3794/johlste.11.7

[16] M. Ottenbacher, R. Harrington and H. G. Parsa, "Defining the Hospitality Discipline: A Discussion of Pedagogical and Research Implications," Journal of Hospitality \& Tourism Research, Vol. 33, No. 3, 2009, pp. 263283. doi:10.1177/1096348009338675

[17] A. Wren, "Scheduling, Timetabling and Rostering-A Special Relationship?” Practice and Theory of Automated Timetabling, Lecture Notes in Computer Science, Vol. 1153, 1996, pp. 46-75.

[18] A. T. Ernst, "Staff Scheduling and Rostering: A Review of Applications, Methods and Models," European Journal of Operational Research, Vol. 153, No. 1, 2004, pp. 3-27. doi:10.1016/S0377-2217(03)00095-X

[19] P. De Causmaecker and G. Vanden Berghe, "Towards a Reference Model for Timetabling and Rostering," Annals of Operations Research, Vol. 194, No. 1, 2008, pp. 167176.

[20] P. Causmaecker and G. Berghe, "A Categorisation of Nurse Rostering Problems," Journal of Scheduling, Vol. 14, No. 1, 2010, pp. 3-16. doi:10.1007/s10951-010-0211-z

[21] N. Gans, G. Koole and A. Mandelbaum, “Telephone Call
Centers: Tutorial, Review, and Research Prospects," Manufacturing and Service Operations Management, Vol. 5, No. 2, 2003, pp. 79-141. doi:10.1287/msom.5.2.79.16071

[22] T. Aykin, "A Comparative Evaluation of Modeling Approaches to the Labor Shift Scheduling Problem,” European Journal of Operational Research, Vol. 125, No. 2, 2000, pp. 381-397. doi:10.1016/S0377-2217(99)00413-0

[23] N. Kohl and S. E. Karisch, "Airline Crew Rostering: Problem Types, Modeling, and Optimization,” Annals of Operations Research, Vol. 127, No. 1-4, 2004, pp. 223257. doi:10.1023/B:ANOR.0000019091.54417.ca

[24] N. Musliu, "Heuristic Methods for Automatic Rotating Workforce Scheduling," International Journal of Computational Intelligence Research, Vol. 2, No. 4, 2006, pp. 309-326. doi:10.5019/j.ijcir.2006.69

[25] K. Choi, J. Hwang and M. Park, "Scheduling Restaurant Workers to Minimize Labor Cost and Meet Service Standards,” Cornell Hospitality Quarterly, Vol. 50, No. 2, 2009, pp. 155-167. doi:10.1177/1938965509333557

[26] P. Eveborn and M. Rönnqvist, "Scheduler-A System for Staff Planning,” Annals of Operations Research, Vol. 128, No. 1-4, 2004, pp. 21-45. doi:10.1023/B:ANOR.0000019097.93634.07

[27] G. M. Thompson, "Controlling Action Times in Daily Workforce Schedules," Cornell Hotel and Restaurant Administration Quarterly, Vol. 37, No. 2, 1996, pp. 8296.

[28] G. M. Thompson, "Labor Scheduling, Part 1: Forecasting Demand," Cornell Hotel and Restaurant Administration Quarterly, Vol. 39, No. 5, 1998, pp. 22-31. doi:10.1177/001088049803900507

[29] G. M. Thompson, "Labor Scheduling, Part 2: Knowing How Many On-duty Employees to Schedule,” Cornell Hotel and Restaurant Administration Quarterly, Vol. 39, No. 5, 1998, pp. 22-31. doi:10.1177/001088049803900507

[30] G. M. Thompson, "Labor Scheduling, Part 3: Developing a Workforce Schedule," Cornell Hotel and Restaurant Administration Quarterly, Vol. 40, No. 1, 1999, pp. 86-96. doi:10.1016/S0010-8804(99)80019-6

[31] G. M. Thompson, "Labor Scheduling, Part 4: Controlling Workforce Schedules in Real Time,” Cornell Hotel and Restaurant Administration Quarterly, Vol. 40, No. 3, 1999, pp. 85-96. doi:10.1177/001088049904000323

[32] M. Warner, "Scheduling Nursing Personnel According to Nursing Preference: A Mathematical Programming Approach,” Operations Research, Vol. 24, No. 5, 1976. doi:10.1287/opre.24.5.842

[33] M. J. Brusco and T. R. Johns, “A Sequential Integer Programming Method for Discontinuous Labor Tour Scheduling,” European Journal of Operational Research, Vol. 95, No. 2, 1996, pp. 537-548.

[34] G. Thompson, "Labor Scheduling Using NPV Estimates of the Marginal Benefit of Additional Labor Capacity," Journal of Operations Management, Vol. 13, No. 1, 1995, pp. 67-86. doi:10.1016/0272-6963(94)00012-4 
[35] G. Thompson and J. Goodale, "Variable Employee Productivity in Workforce Scheduling," European Journal of Operational Research, Vol. 170, No. 2, 2006, pp. 376390. doi:10.1016/j.ejor.2004.03.048

[36] A. Rong, "Monthly Tour Scheduling Models with Mixed Skills Considering Weekend off Requirements," Computers \& Industrial Engineering, Vol. 59, No. 2, 2010, pp. 334-343. doi:10.1016/j.cie.2010.05.005

[37] F. F. Easton and D. F. Rossin, "A Stochastic Goal Program for Employee Scheduling,” Decision Sciences, Vol. 27, No. 3, 1996, pp. 541-568. doi:10.1111/j.1540-5915.1996.tb01825.x

[38] G. Thompson and M. Pullman, "Scheduling Workforce Relief Breaks in Advance versus in Real-Time," European Journal of Operational Research, Vol. 181, No. 1, 2007, pp. 139-155. doi:10.1016/j.ejor.2006.05.018

[39] L. W. Jacobs and M. J. Brusco, "Overlapping Start-Time Bands in Implicit Tour Scheduling," Management Science, Vol. 42, No. 9, 1996, pp. 1247-1259. doi:10.1287/mnsc.42.9.1247

[40] M. J. Brusco and L. W. Jacobs, "Personnel Tour Scheduling When Starting-Time Restrictions Are Present," Management Science, Vol. 44, No. 4, 1998, pp. 534-547. doi:10.1287/mnsc.44.4.534

[41] H. K. Alfares, "Survey, Categorization, and Comparison of Recent Tour Scheduling Literature,” Annals of Operations Research, Vol. 127, No. 1-4, 2004, pp. 145-175. doi:10.1023/B:ANOR.0000019088.98647.e2

[42] G. B. Dantzig, “A Comment on Edie's 'Traffic Delays at Toll Booths'," Journal of the Operations Research Society of America, Vol. 2, No. 3, 1954, pp. 339-341.

[43] B. Cheang, "Nurse Rostering Problems-A Bibliographic Survey,” European Journal of Operational Research, Vol. 151, No. 3, 2003, pp. 447-460. doi:10.1016/S0377-2217(03)00021-3

[44] E. K. Burke, P. De Causmaecker, G. V. Berghe and H. Van Landeghem, "The State of the Art of Nurse Roster- ing,” Journal of Scheduling, Vol. 7, No. 6, 2004, pp. 441499. doi:10.1023/B:JOSH.0000046076.75950.0b

[45] M. W. Isken, “An Implicit Tour Scheduling Model with Applications in Healthcare," Annals of Operations Research, Vol. 128, No. 1-4, 2004, pp. 91-109. doi:10.1023/B:ANOR.0000019100.08333.a7

[46] J. C. Goodale and G. M. Thompson, “A Comparison of Heuristics for Assigning Individual Employees to Labor Tour Schedules,” Annals of Operations Research, Vol. 128, No. 1-4, 2004, pp. 47-63. doi:10.1023/B:ANOR.0000019098.97205.cc

[47] M. J. Brusco and L. W. Jacobs, "Cost Analysis of Alternative Formulations for Personnel Scheduling in Continuously Operating Organizations," European Journal of Operational Research, Vol. 86, No. 2, 1995, pp. 249-261. doi:10.1016/0377-2217(94)00063-I

[48] K. A. Dowsland, "Nurse Scheduling with Tanu Search and Strategic Oscillation,” European Journal of Operational Research, Vol. 106, 1998, pp. 393-407. doi:10.1016/S0377-2217(97)00281-6

[49] U. Aickelin and K. A. Dowsland, "Exploiting Problem Structure in a Genetic Algorithm Approach to a Nurse Rostering Problem,” Journal of Scheduling, Vol. 3, No. 3, 2008, pp. 139-153. doi:10.1002/(SICI)1099-1425(200005/06)3:3<139::AID-J OS41>3.0.CO;2-2

[50] E. K. Burke, J. Li and R. Qu, "A Hybrid Model of Integer Programming and Variable Neighbourhood Search for Highly-Constrained Nurse Rostering Problems," European Journal of Operational Research, Vol. 203, No. 2, 2010, pp. 484-493. doi:10.1016/j.ejor.2009.07.036

[51] I. Blochliger, "Modeling Staff Scheduling Problems. A Tutorial,” European Journal of Operational Research, Vol. 158, No. 3, 2004, pp. 533-542. doi:10.1016/S0377-2217(03)00387-4

[52] E. G. Keith, “Operator Scheduling,” IIE Transactions, Vol. 11, No. 1, 1979, pp. 37-41. 